\title{
Empirical eradication therapy was better than endoscopy based management for Helicobacter pylori infection and dyspepsia
}

\author{
Heaney A, Collins JS, Watson RG, et al. A prospective randomised trial of a "test and treat" policy versus endoscopy based \\ management in young Helicobacter pylori positive patients with ulcer-like dyspepsia, referred to a hospital clinic. Gut \\ 1999 Aug;45:186-90.
}

QUESTION: In younger patients with Helicobacter pylori infection and dyspepsia, is empirical eradication therapy better than an endoscopy based management strategy for reducing dyspepsia and improving quality of life?

Design

Randomised (unclear allocation concealment*), unblinded,* controlled trial with 12 month follow up.

\section{Setting}

Gastroenterology clinics of 2 hospitals in Belfast, Northern Ireland, United Kingdom.

\section{Patients}

104 patients who had ulcer-like dyspepsia and were $\leq 45$ years of age (mean age $32 \mathrm{y}, 57 \%$ men). Exclusion criteria were weight loss, dysphagia, symptoms of gastroesophageal reflux disease, history of gastrointestinal bleeding, regular use of non-steroidal antiinflammatory drugs, gallstone symptoms, pregnancy, and $H$. pylori eradication treatment in the previous 2 weeks. Follow up was $96 \%$.

\section{Intervention}

After stratification for sex and tobacco and alcohol use, patients were allocated to empirical eradication therapy $(\mathrm{n}=52)$ or oesophagogastroduodenoscopy (OGD) $(\mathrm{n}=52)$. In the OGD group, eradication therapy was given according to type of diagnosis. Empirical eradication therapy consisted of 1 week triple therapy: omeprazole, $20 \mathrm{mg}$ twice daily; clarithromycin, $250 \mathrm{mg}$ twice daily; and tinidazole, $500 \mathrm{mg}$ twice daily.

\section{Main outcome measures}

Dyspepsia symptoms (Glasgow dyspepsia severity score) and quality of life (Short Form-36 health survey).

Source of funding: not stated.

For correspondence: Dr A Heaney, Royal Victoria Hospital, Belfast BT12 6BA Northern Ireland, UK.

\section{Main results}

At 12 months, dyspepsia symptom scores $(\mathrm{p}<0.05)$ and quality of life scores for physical function $(\mathrm{p}<0.05)$ were better in the empirical eradication group than in the OGD group (table).

\section{Conclusion}

In younger patients with $H$. pylori infection and dyspepsia, empirical eradication therapy for 1 week was better than an endoscopy based management strategy for reducing dyspeptic symptoms and improving physical function.

*See glossary.

\section{COMMENTARY}

Several working groups have recommended a strategy of testing and treating $\mathrm{H}$. pylori infection in younger patients who have dyspepsia without alarm symptoms. ${ }^{12}$ The study by Heaney and colleagues provides more empirical support for testing and treating than for endoscopy. Both strategies were safe, but $43 \%$ of patients were symptom free and $76 \%$ did not require antisecretory therapy at 12 months in the test and treat arm compared with $30 \%$ and $63 \%$, respectively, in the OGD group. Although these results can be best applied to secondary care, a recent study in primary care adds further support for the generalisability of the findings.

Why was empirical therapy superior to endoscopy in these patients? This finding probably does not reflect a substantial effect of eradication therapy on patients with non-ulcer dyspepsia. ${ }^{4}$ Whether lack of blinding biased the outcome is uncertain. Notably, a high background rate of peptic ulcer existed in the evaluated patients ( $47 \%$ in the endoscopy group). It is conceivable that eradication therapy would be more successful in patients with a high background rate of peptic ulcer because patients in the OGD group with healed ulcers would have been misdiagnosed as having non-ulcer dyspepsia and would not have been offered eradication therapy.

Reassurance was not evaluated in this study. Others have observed that reassurance is greater in patients receiving endoscopy, ${ }^{5}$ but symptom improvement is likely to parallel satisfaction scores.

On the basis of available data, the standard of care for young, healthy people with dyspepsia should be testing and treating. Long term outcome data are still required, however, to better understand the effect of this strategy in practice.

Nicholas J Talley, MD, PhD University of Sydney

Sydney, New South Wales, Australia

1 Talley NJ, Silverstein MD, Agreus L, et al. Gastroenterology 1998;114:582-95.

2 Talley NJ, Axon A, Bytzer P, et al. Aliment Pharmacol Ther 1999;13:1135-48.

3 Jones R, Tate C, Sladen G, Weston-Baker J. Int J Clin Pract 1999;53:413-16.

4 Talley NJ, Vakil N, Ballard ED 2d, et al. N Engl J Med 1999;341:1106-11.

5 Bytzer P, Hansen JM, Schaffalitzky de Muckadell OB. Lancet 1994;343:811-16.

\begin{tabular}{llrr} 
Dyspepsia symptoms & Glasgow dyspepsia severity score & 3.37 & 5.08 \\
\hline Quality of life-physical function & Short Form-36 health survey & 91.88 & 81.96 \\
\hline
\end{tabular}

